\title{
Letter
}

Diabetes Metab J 2021;45:454-456

https://doi.org/10.4093/dmj.2021.0068

pISSN 2233-6079 · eISSN 2233-6087

DIABET\&S \& METABOLISM JOURNAL

\section{Status of Diabetic Neuropathy in Korea: A National Health Insurance Service-National Sample Cohort Analysis (2006 to 2015) (Diabetes Metab J 2021;45:115-9)}

\author{
Tímea Csákvári ${ }^{1}$, Diána Elmer², Lilla Horváth ${ }^{2}$, Imre Boncz ${ }^{2}$ \\ ${ }^{1}$ University of Pécs, Faculty of Health Sciences, Institute for Health Insurance, Zalaegerszeg, \\ ${ }^{2}$ University of Pécs, Faculty of Health Sciences, Institute for Health Insurance, Pécs, Hungary
}

Health insurance costs of diseases that pose a significant public health burden provide decision-makers important information not only in terms of the epidemiological consequences but also regarding their economic impact. Studying changes in this respect over a longer period of time focusing on diseases causing a significant health burden may reveal valuable information and thus, may help identify and predict trends that can subsequently contribute to designing and implementing actions that target the reduction of the disease burden related to these medical conditions.

In 2019, diabetes affected around 463 million people worldwide [1]. Nerve damage as a microvascular complication is the most common complication among diabetic patients. Diabetic neuropathy (DN) is the most common cause of non-traumatic lower extremity amputations [2]. In a study, Moon et al. [3] focused on neuropathy as the most prevalent complication of diabetes mellitus. The strength of the study is that the prevalence of the disease/complication was investigated on a representative cohort sample. Authors found that the prevalence of neuropathy showed a decreasing tendency after 2007 (2007, $26.6 \% ; 2015,20.8 \%)$. According to estimates published in the international literature, the prevalence of painful neuropathy is between $5.8 \%$ and $34 \%$ in the European diabetic population [4]. Although these estimates are in line with findings of the above study, authors highlight the fact that these numbers may actually be higher.

We have previously studied the epidemiological and disease burden of type 2 diabetes mellitus (T2DM) with neurological complications and diabetic polyneuropathy (DPN) in Hungary $[5,6]$. Data were derived from the database of the National Health Insurance Fund Administration (NHIFA), the sole health insurance provider of Hungary that allowed us to perform a comprehensive nationwide analysis.

The table below shows the distribution of International Classification of Diseases (ICD) codes E11.4 and G63.2 that may identify nerve damage related to T2DM in Hungary according to levels of care (Table 1) [7]. In 2018, the health insurance treatment cost of non-insulin dependent diabetes mellitus with neurological complications (E11.4) was 12.22 million United States dollar (USD) in Hungary, its prevalence was 365.9/100.000 in women and 350.5/10.000 in men amounting to a total of 358.5/ 100.000. The NHIFA spent 24.52 million USD on the treatment of DPN (G63.2) in the same year. Based on costs of pharmaceuticals, the prevalence of DPN for the entire population was 838.6/100.000 in men and 972.3/100.000 in women accounting for a total of $908.4 / 100,000$.

Diabetic foot syndrome is the most severe condition related to diabetes and its neurological complications and requires a complex therapy [8]. The presence of neuropathy has been proved to contribute to the development of diabetic foot syn-
Corresponding author: Tímea Csákvári (iD https://orcid.org/0000-0002-3339-4953 University of Pécs, Faculty of Health Sciences, Institute for Health Insurance, 33 Landorhegyi street, Zalaegerszeg H-8900, Hungary

E-mail: timea.csakvari@etk.pte.hu
This is an Open Access article distributed under the terms of the Creative Commons Attribution Non-Commercial License (https://creativecommons.org/licenses/by-nc/4.0/) which permits unrestricted non-commercial use, distribution, and reproduction in any medium, provided the original work is properly cited. 
Table 1. National patient numbers reported under codes identifying types of non-insulin dependent diabetes mellitus and health insurance costs in Hungary, in 2018

\begin{tabular}{|c|c|c|c|c|}
\hline \multirow{2}{*}{ Type of care } & \multicolumn{2}{|c|}{$\begin{array}{l}\text { E11.4 Non-insulin dependent diabetes mellitus with } \\
\text { neurological complications }\end{array}$} & \multicolumn{2}{|c|}{ G63.2 Diabetic polyneuropathy } \\
\hline & $\begin{array}{l}\text { Patient numbers } \\
\text { (persons) }\end{array}$ & $\begin{array}{l}\text { Costs, } \\
\text { USD }\end{array}$ & $\begin{array}{l}\text { Patient numbers } \\
\text { (persons) }\end{array}$ & $\begin{array}{l}\text { Costs, } \\
\text { USD }\end{array}$ \\
\hline General practice care & 40,323 & 664,253 & 91,550 & $1,582,830$ \\
\hline Specialised home care & 47 & 15,076 & 74 & 21,333 \\
\hline Patient transport & 263 & 11,521 & 434 & 22,816 \\
\hline Outpatient specialist care & 42,447 & 964,137 & 90,365 & $2,621,930$ \\
\hline Care home residential care & 71 & 4,444 & 157 & 10,051 \\
\hline Laboratory diagnostics & 18,738 & 71,130 & 24,992 & 14,213 \\
\hline CT, MRI & 111 & 11,573 & 398 & 36,570 \\
\hline Acute inpatient care & 671 & 285,489 & 0 & 0 \\
\hline Chronic inpatient specialist care & 71 & 19,820 & 1 & 2,887 \\
\hline Cost of pharmaceuticals & 35,057 & $9,640,287$ & 88,826 & $19,199,863$ \\
\hline Cost of medical aids & 7,093 & 532,638 & 4,624 & $1,011,102$ \\
\hline Total & - & $12,220,369$ & - & $24,523,596$ \\
\hline
\end{tabular}

Adapted from National Health Insurance Fund Administration of Hungary [7].

USD, United States dollar; CT, computed tomography; MRI, magnetic resonance imaging.

drome and has been found to be the underlying cause in approximately half of the cases [9]. Determining the exact incidence and prevalence of diabetic foot is quite difficult as it is a multifactorial condition and as there is no specific ICD code for it (though, ICD-11 does include a code for diabetic foot ulcer and also for Charcot foot). It is important to note, that patients suffering from neuropathy who are identified with codes E10.7-E14.7E as for the primary diagnosis may also be having the syndrome. Upon studying neurological complications, it is thus, important to consider cases where ICD codes E10.4E14.4 appear as comorbidities.

A further limitation is that besides ICD codes studied by the authors other codes may also be used for neurological complications (e.g., G73.0: diabetic amyotrophy; or E10.7-E14.7: diabetes mellitus with multiple complications; E10.8-E14.8: diabetes mellitus with unspecified complications).

Authors studied the prevalence of $\mathrm{DN}$ in a population above 30 years. (Poly)neuropathy is first diagnosed many years after the onset of diabetes. It is important to emphasise the fact that childhood onset diabetes mellitus is a significant and growing problem worldwide. According to a study summarising the results of the SEARCH for Diabetes in Youth (SEARCH) study, DN was found in $7 \%$ of young people with T1DM and in $22 \%$ of those suffering from T2DM [10].

According to Moon et al. [3], in the cohort sample, the prevalence of DN was 20.8\% among diabetics (aged above 30 years) in 2015. Based on our nationwide data, the prevalence of T2DM with neurological complications within the diabetic population was $4.20 \%$ (males $4.14 \%$, females $4.25 \%$ ), while that of DPN was $8.94 \%$ (males $8.53 \%$, females $9.30 \%$ ), in total $13.14 \%$ (males $12.67 \%$, females $13.56 \%$ ) in 2018. Our results revealed lower prevalence rates for both diseases as compared to Korean data.

Authors revealed prescription rates varying between $66.5 \%$ and $69.0 \%$ during the 10 -year period analysed. In Hungary, in the case of 'E11.4 non-insulin dependent diabetes mellitus with neurological complications' out of 42.447 outpatients, $82.59 \%$, i.e., 35.057 patients were prescribed pharmaceuticals. With a diagnosis coded 'G63.2 Diabetic polyneuropathy' out of 91.550 outpatients 88.826 , i.e., $97.02 \%$ received a prescription. The above finding demonstrates that Hungary has higher prescription rates compared to Korea.

Prevalence data published by Moon et al. [3] on diabetic retinopathy (males $12.6 \%$ to $15.1 \%$, females $14.7 \%$ to $17.4 \%$ ) and nephropathy (males $8.6 \%$ to $12.9 \%$, females $8.1 \%$ to $11.8 \%$ ) for the same time period were considerably higher than Hungari- 
an rates in 2018 (retinopathy: males $0.94 \%$, females $1.00 \%$; nephropathy: males $1.72 \%$, females $1.36 \%$ ).

In conclusion, our study has proved that analysing data collected by observing strict inclusion criteria (pharmaceutical prescription rates, ICD codes) on a large representative cohort, including patient registers or real world health insurance claims data can provide the most relevant and reliable information that may significantly contribute to efforts aimed at lowering the economic and societal burden of a given medical condition.

\section{CONFLICTS OF INTEREST}

No potential conflict of interest relevant to this article was reported.

\section{FUNDING}

The research was financed by the Thematic Excellence Program 2020-Institutional Excellence Sub-programme/National Excellence Sub-program of the Ministry for Innovation and Technology in Hungary, within the framework of the Biomedical Engineering and 2nd thematic programme of the University of Pécs (Code: 2020-4.1.1-TEP2020). The funders had no role in study design, data collection and analysis, decision to publish, or preparation of the manuscript.

\section{REFERENCES}

1. International Diabetes Federation. IDF diabetes atlas. 9th ed. Brussels: IDF; 2019 [cited 2021 May 13]. Available from: https://www.diabetesatlas.org.
2. Abola MT, Bhatt DL, Duval S, Cacoub PP, Baumgartner I, Keo $\mathrm{H}$, et al. Fate of individuals with ischemic amputations in the REACH Registry: three-year cardiovascular and limb-related outcomes. Atherosclerosis 2012;221:527-35.

3. Moon SS, Kim CH, Kang SM, Kim ES, Oh TJ, Yun JS, et al. Status of diabetic neuropathy in Korea: a National Health Insurance Service-National Sample Cohort Analysis (2006 to 2015). Diabetes Metab J 2021;45:115-9.

4. Alleman CJ, Westerhout KY, Hensen M, Chambers C, Stoker $\mathrm{M}$, Long $\mathrm{S}$, et al. Humanistic and economic burden of painful diabetic peripheral neuropathy in Europe: a review of the literature. Diabetes Res Clin Pract 2015;109:215-25.

5. Boncz I, Ponusz R, Elmer D, Nemeth N, Horvath L, Sebestyen A, et al. Annual health insurance treatment cost of diabetic polyneuropathy based on routinely collected financing data. Value Health 2020;23(Suppl 1):S117.

6. Boncz I, Ponusz R, Elmer D, Nemeth N, Horvath L, Sebestyen A, et al. Epidemiological disease burden of diabetic polyneuropathy based on routinely collected health insurance claims data. Value Health 2020;23(Suppl 1):S121-2.

7. National Health Insurance Fund of Hungary: Own calculation based on the data of the National Health Insurance Fund Administration, Hungary. Available from: www.neak.gov.hu (cited 2021 May 13).

8. Apelqvist J. Diagnostics and treatment of the diabetic foot. Endocrine 2012;41:384-97.

9. Volmer-Thole M, Lobmann R. Neuropathy and diabetic foot syndrome. Int J Mol Sci 2016;17:917.

10. Jaiswal M, Divers J, Dabelea D, Isom S, Bell RA, Martin CL, et al. Prevalence of and risk factors for diabetic peripheral neuropathy in youth with type 1 and type 2 diabetes: SEARCH for diabetes in youth study. Diabetes Care 2017;40:1226-32. 